\title{
A Novel Structure for Vector Control of Symmetrical Six-Phase Induction Machines with Three Current Sensors
}

\author{
Hamidreza Pairodin Nabi \\ Departement of Electrical Engineering \\ Iran University of Science and \\ Technology (IUST) \\ Tehran,Iran \\ h_pairo@elec.iust.ac.ir
}

\author{
Pooya Dadashi \\ Departement of Electrical Engineering \\ Iran University of Science and \\ Technology (IUST) \\ Tehran,Iran \\ pooyadadashi@yahoo.com
}

\author{
Abbas Shoulaie \\ Departement of Electrical Engineering \\ Iran University of Science and \\ Technology (IUST) \\ Tehran,Iran \\ shoulaie@ iust.ac.ir
}

\begin{abstract}
Vector control is one of the most popular multiphase induction machine drive methods due to its dynamic performance. Since all phase currents are needed in vector control drive, by increasing phase numbers, the number of required current sensors increases which is one of the disadvantages of vector control in multiphase machine drives. In this paper vector control of a symmetrical six-phase induction machine with a novel configuration is presented. The aforementioned configuration is designed in a simple way that only three current sensors will be needed. Analytical equations are extracted in this paper to show that some of current components which do not contribute in torque production will be eliminated due to the proposed scheme. Simulation and experimental results are provided to verify the benefits of the proposed configuration.
\end{abstract}

Keywords- Symmetrical six-phase induction machine; Vector control; Current sensor; Multiphase drives.

\section{INTRODUCTION}

In early 1990 s, study on multiphase machines accelerated; until the beginning of recent century, it became practical in industries. Multiphase induction machines are predominantly used in electric ship propulsion, traction and generally in high power applications [1-3]. Multiphase induction machines have some advantages over three phase induction machines. Employing multi-phase induction machines would reduce the pulsating torque and would increase the efficiency of the machine. Six-phase induction machines have $6.7 \%$ reduction in stator copper loss compared to the same machine wound with an equivalent three-phase winding of the same pitch [4-5]. Also, multiphase induction machines have less noise pollution compared to three-phase ones [6]. Among several benefits, high phase numbers provide better motor performance following loss of one or more phases; in addition using multiphase induction machines obtain the capability to start and run even with some phases open circuited [7-9].

The other advantage is the improvement of torque in multiphase machines with concentrated winding. Lyra et al. [10] showed that additional torque production can be obtained by injecting third harmonic current.

Also, increasing phase number to at least five (or more) enables completely independent vector control of two (or more) multiphase machines that are supplied from a single current-controlled voltage source inverter [11-12]. Further, the switched voltage profile in the motors' windings and their behaviour is evaluated in [13] to achieve independent feed forward voltage control of two series connected six-phase and three-phase induction machines.

Recently, several control techniques are considered about induction machines which application of each method depends on desired specific condition [14-15]. One of these methods is called scalar and it is more suitable for low power applications [16]. In contrast, vector control of induction machines was introduced by Blaschke [17] and Hasse [18] which has better dynamic response. Despite of the higher phase number in multiphase induction machines, they have more degrees of freedom. Nevertheless, all these techniques are applicable for multiphase induction machines with little differences [19].

A specific problem encountered in multiphase drive systems is that generation of certain low-order voltage harmonics in the voltage source inverter output. Low-order stator voltage harmonics maps into $x-y$ components using ordinary reference frame technique. According to the possibility of flowing $x-y$ current components, the tendency is to create sinusoidal voltage at the output of the inverter. The existence of low order harmonics in input supply leads to large stator current harmonics which only restricted by stator leakage impedance [20]; whereas machines with sinusoidal MMF distribution have very small impedance for $x-y$ voltage components [2]. Although with non-sinusoidal voltage source, multiphase machines generally have more stator copper loss, but they always have less rotor copper loss versus three phase machines [21].

The asymmetrical six-phase induction machines (two threephase with $30^{\circ}$ displacement) are the most frequently 
considered multiphase machines in industrial applications. The choice of asymmetrical six-phase machine rather than symmetrical (two three-phase with $60^{\circ}$ displacement) is for existence of sixth harmonic of torque caused by the fifth and seventh harmonics of the stator current in symmetrical ones. However, implementation of proper PWM strategy, with sufficiently high switching frequency, leads to the same performance of symmetrical and asymmetrical six-phase machines for a six-phase VSI [19]. In this context, excellent high performance quality of rotor flux oriented control of a symmetrical six-phase induction machine has been demonstrated in [22].

With advances in power semiconductor technology and improvement in control methods, the trend to low cost drive systems is increased. By reducing the number of equipments used in these systems, the final cost will be reduced too. Reduction in the number of current sensors will result in lower cost of these drive systems. In [23] a rotor field-oriented control of dual-three-phase induction machine, employing only two current sensors, has been presented. A novel torque and speed control structure for low-cost induction machine drive with a single dc-link current sensor presented in [24].

In vector control of symmetrical six-phase machines, in regular manner, we need at least five current sensors. In this paper, proposed configuration of symmetrical six-phase induction machine leads to minimizing the number of current sensors which only three current sensors will be needed.

\section{INDIRECT VECTOR CONTROL OF MULTIPHASE INDUCTION MACHINES}

The main objective of vector control of induction machines is to control them like separately excited dc machines. In this section, the model of a symmetrical six-phase induction machine and its vector control algorithm will be presented.

\section{A. Six-phase Machine Model}

An induction machine can be modelled with state-space equations. In these equations, voltage and frequency are as inputs and the outputs of the state-space equations are speed, position, torque, flux, current or a combination of them. The stator equations in arbitrary common reference frame are shown in equation (1) [12]:

$$
\begin{array}{ll}
V_{d s}=R_{s} i_{d s}-\omega_{s} \lambda_{q s}+\frac{d \lambda_{d s}}{d t} \quad, \quad \lambda_{d s}=\left(L_{l s}+L_{m}\right) i_{d s}+L_{m} i_{d r} \\
V_{q s}=R_{s} i_{q s}+\omega_{s} \lambda_{d s}+\frac{d \lambda_{q s}}{d t} \quad, & \lambda_{q s}=\left(L_{l s}+L_{m}\right) i_{q s}+L_{m} i_{q r} \\
V_{x 1}=R_{s} i_{x 1 s}+\frac{d \lambda_{x 1 s}}{d t} & , \lambda_{x 1 s}=L_{l s} i_{x 1 s} \\
V_{y 1}=R_{s} i_{y 1 s}+\frac{d \lambda_{y 1 s}}{d t} & , \lambda_{y 1 s}=L_{l s} i_{y 1 s} \\
V_{0+s}=R_{s} i_{0+s}+\frac{d \lambda_{0+s}}{d t} & , \lambda_{0+s}=L_{l s} i_{0+s} \\
V_{0-s}=R_{s} i_{0-s}+\frac{d \lambda_{0-s}}{d t} & , \lambda_{0-s}=L_{l s} i_{0-s}
\end{array}
$$

And rotor equations are as follows:

$$
\begin{array}{ll}
V_{d r}=0=R_{r} i_{d r}-\left(\omega_{s}-\omega_{r}\right) \lambda_{q r}+\frac{d \lambda_{d r}}{d t}, \lambda_{d r}=\left(L_{l r}+L_{m}\right) i_{d r}+L_{m} i_{d s} \\
V_{q r}=0=R_{s} i_{q r}+\left(\omega_{s}-\omega_{r}\right) \lambda_{d r}+\frac{d \lambda_{q r}}{d t}, \lambda_{q r}=\left(L_{l r}+L_{m}\right) i_{q r}+L_{m} i_{q s} \\
V_{x 1 r}=0=R_{r} i_{x 1 r}+\frac{d \lambda_{x 1 r}}{d t} \quad, \quad \lambda_{x 1 r}=L_{l r} i_{x 1 r} \\
V_{y 1 r}=0=R_{r} i_{y 1 r}+\frac{d \lambda_{y 1 r}}{d t} \quad, \quad \lambda_{y 1 r}=L_{l r} i_{y 1 r} \\
V_{0+r}=0=R_{r} i_{0+r}+\frac{d \lambda_{0+r}}{d t} \quad, \quad \lambda_{x 1 r}=L_{l r} i_{0+r} \\
V_{0-r}=0=R_{r} i_{0-r}+\frac{d \lambda_{0-r}}{d t} \quad, \quad \lambda_{0-r}=L_{l r} i_{0-r}
\end{array}
$$

In these equations, the various symbols denote the following: $\mathrm{R}_{\mathrm{s}}$, the stator resistance per phase; $\mathrm{R}_{\mathrm{r}}$, the referred rotor resistance per phase; $L_{m}$, the mutual inductance per phase; Lls, the stator leakage inductance per phase; $\mathrm{L}_{\mathrm{lr}}$, the stator referred rotor leakage inductance per phase; $\omega_{s}$ and $\omega_{r}$ are synchronous speed and electrical rotor speed both in $\mathrm{rad} / \mathrm{sec}$. it should be noted that $L_{m}$ is equal to $3 M$ which $M$ is the maximum mutual inductance value between stator and rotor. The torque equation is as follows:

$$
T_{e}=P L_{m}\left[i_{d r} i_{q s}-i_{d s} i_{q r}\right]
$$

\section{B. Six-phase induction machine vector control algorithm}

Since the considered induction machine is symmetrical with sinusoidally stator winding, then the only difference between vector control scheme of a three-phase and six-phase induction machine is due to the decoupling transformation matrix [19]. In vector control of induction machines, the direct axis should be aligned with rotor flux vector, and then the quadrature component of rotor flux will be equal to zero:

$$
\begin{aligned}
& \lambda_{r}=\lambda_{d r} \\
& \lambda_{q r}=L_{m} i_{q s}+\left(L_{l r}+L_{m}\right) i_{q r}=0 \\
& i_{q r}=-\frac{L_{m}}{L_{l r}+L_{m}} i_{q s} \\
& \lambda_{q r}=0 \\
& \frac{d}{d t} \lambda_{q r}=0
\end{aligned}
$$

By substituting the equation (4) in equation (2), the followings are obtained:

$$
\begin{aligned}
& i_{d s}=\frac{1}{L_{m}}\left[1+T_{r} \frac{d}{d t}\right] \lambda_{r} \\
& \omega_{s}-\omega_{r}=\frac{1}{T_{r}} \cdot \frac{i_{q s}}{i_{d s}}
\end{aligned}
$$

It should be noted that, in these equations, rotor time constant, $\mathrm{T}_{\mathrm{r}}$, is equal to $\left(\left(L_{l r}+L_{m}\right) / R_{r}\right)$. Under these conditions, with using equations (3) and (4), the torque equation will become as: 


$$
T_{e}=K \lambda_{d r} i_{q s}
$$

Where $\mathrm{K}$ is torque constant. This equation shows that if rotor flux will not be distorted, then the quadrature component of the stator current, $\mathrm{i}_{\mathrm{qs}}$, can control the torque and the rotor flux can be controlled with direct component of stator current [25]. Proper performance of control system and using correct estimated parameters ensure that rotor flux will not be distorted.

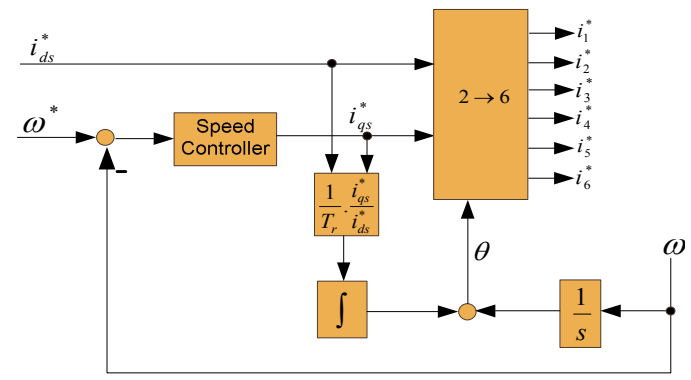

Fig. 1. Indirect vector control diagram of six-phase induction machine

\section{PROPOSED STRUCTURE FOR MINIMIZING THE} INDEPENDENT CURRENTS IN SIX-PHASE INDUCTION MACHINES

In this section, the proposed structure for reducing current sensors is considered. The current references in the block diagram of Figure 1 are as follows:

$$
\begin{aligned}
i_{1}^{*} & =\sqrt{\frac{2}{6}}\left(i_{d s}^{*} \cos \theta-i_{q s}^{*} \sin \theta\right) \\
i_{2}^{*} & =\sqrt{\frac{2}{6}}\left(i_{d s}^{*} \cos \left(\theta-\frac{2 \pi}{6}\right)-i_{q s}^{*} \sin \left(\theta-\frac{2 \pi}{6}\right)\right) \\
& \vdots \\
i_{6}^{*} & =\sqrt{\frac{2}{6}}\left(i_{d s}^{*} \cos \left(\theta-\frac{10 \pi}{6}\right)-i_{q s}^{*} \sin \left(\theta-\frac{10 \pi}{6}\right)\right)
\end{aligned}
$$

The proposed structure is based on the connection diagram of six-phase induction machines. Figure 2 shows two different connection diagram of six-phase induction machine. Figure 2(a) shows the star-connected six-phase induction machine and Figure 2(b) illustrates the proposed structure. If the current references of equation (7) will be applied to a machine with configuration of Figure 2(a), then the relation between motor currents would be as:

$$
i_{1}+i_{2}+\ldots+i_{6}=0 \rightarrow i_{1}=-i_{2}-i_{3}-\ldots-i_{6}
$$

This equation shows that there are five independent currents for a six-phase machine. Respectively, according to the structure of Figure 2(a), just a single current sensor can be eliminated.

In symmetrical six-phase induction machines, under symmetrical and balanced source, the current of mth phase is equal to the negative of the $(m+3)$ th phase current $\left(i_{m}=-i_{(m+3)}\right)$.
So in six-phase induction machines, there is the possibility of using the structure of Figure 2(b). As shown in Figure 2(b), the second end of $m$ th phase is directly connected the second end of $(m+3)$ th phase $(m=1,2$, and 3$)$. Hence, it is clear that the current of $m$ th phase is instantaneously equal to the current of $(m+3)$ th phase. So the relation between phase currents will be as follows:

$$
\begin{aligned}
& i_{1}=-i_{4} \\
& i_{2}=-i_{5} \\
& i_{3}=-i_{6}
\end{aligned}
$$

This equation shows that with using the structure of Figure 2(b), the number of independent currents will be equal to three and consequently the number of current sensors can be reduced to three sensors.

\section{ANALYSIS OF THE PROPOSED STRUCTURE}

In this section, the effect of this structure on the different current components of six-phase induction machines is considered. For this purpose, the currents of six-phase induction machines are transformed using decoupling transformation matrix of equation (10) [26].

$$
\begin{aligned}
\alpha \\
\beta
\end{aligned}\left[\begin{array}{ccccccc}
1 & \cos \alpha & \cos 2 \alpha & \cos 3 \alpha & \cos 4 \alpha & \cos 5 \alpha \\
0 & \sin \alpha & \sin 2 \alpha & \sin 3 \alpha & \sin 4 \alpha & \sin 5 \alpha \\
\frac{2}{6} & x 1 & y 1 \\
1 & \cos 2 \alpha & \cos 4 \alpha & \cos 6 \alpha & \cos 8 \alpha & \cos 10 \alpha \\
0 & \sin 2 \alpha & \sin 4 \alpha & \sin 6 \alpha & \sin 8 \alpha & \sin 10 \alpha \\
1 / \sqrt{2} & 1 / \sqrt{2} & 1 / \sqrt{2} & 1 / \sqrt{2} & 1 / \sqrt{2} & 1 / \sqrt{2} \\
0- & -\sqrt{2} & -1 / \sqrt{2} & 1 / \sqrt{2} & -1 / \sqrt{2} & 1 / \sqrt{2} & -1 / \sqrt{2}
\end{array}\right]
$$

Where in this equation $\alpha=2 \pi / 6$. By applying the matrix of equation (10), the $\alpha-\beta$ current components will be as:

$$
\begin{aligned}
& i_{\alpha}=i_{1}+i_{2} \cos (\alpha)+\ldots+i_{6} \cos (5 \alpha) \\
& i_{\beta}=0+i_{2} \sin (\alpha)+\ldots+i_{6} \sin (5 \alpha)
\end{aligned}
$$

With substituting equation (9) in equation (11), the followings are obtained:

$$
\begin{aligned}
i_{\alpha}= & i_{1}[1-\cos (3 \alpha)]+i_{2}[\cos (\alpha)-\cos (4 \alpha)] \\
& +i_{3}[\cos (2 \alpha)-\cos (5 \alpha)] \\
i_{\beta}= & i_{1}[0-\sin (3 \alpha)]+i_{2}[\sin (\alpha)-\sin (4 \alpha)] \\
& +i_{3}[\sin (2 \alpha)-\sin (5 \alpha)]
\end{aligned}
$$

It is clear that $\cos ((m-1) \alpha)=-\cos ((m+2) \alpha)$ and $\sin ((m-1) \alpha)=-\sin ((m+2) \alpha)$ which $\mathrm{m}=1,2$, and 3. So, it would be concluded that:

$$
\begin{aligned}
& i_{\alpha}=2 i_{1}+2 i_{2} \cos (\alpha)+2 i_{3} \cos (2 \alpha) \\
& i_{\beta}=0+2 i_{2} \sin (\alpha)+2 i_{3} \sin (2 \alpha)
\end{aligned}
$$

For considering the effect of this structure on the $\mathrm{x} 1-\mathrm{y} 1$ current components, the $\mathrm{x} 1-\mathrm{y} 1$ current component equations 
are considered. The general form of $\mathrm{x} 1-\mathrm{y} 1$ current components will be as follows:

$$
\begin{aligned}
& i_{x 1}=i_{1}+i_{2} \cos (2 \alpha)+\ldots+i_{6} \cos (10 \alpha) \\
& i_{y 1}=0+i_{2} \sin (2 \alpha)+\ldots+i_{6} \sin (10 \alpha)
\end{aligned}
$$

By substituting equation (9) in equation (13), it would be concluded that:

$$
\begin{aligned}
i_{x 1}= & i_{1}[1-\cos (6 \alpha)]+i_{2}[\cos (2 \alpha)-\cos (8 \alpha)] \\
& +i_{3}[\cos (4 \alpha)-\cos (10 \alpha)] \\
i_{y 1}= & i_{1}[0-\sin (6 \alpha)]+i_{2}[\sin (2 \alpha)-\sin (8 \alpha)] \\
& +i_{3}[\sin (4 \alpha)-\sin (10 \alpha)]
\end{aligned}
$$

And simply, the followings are obtained:

$$
\begin{aligned}
\cos (2(m-1) \alpha) & =\cos (2(m+2) \alpha) \\
\sin (2(m-1) \alpha) & =\sin (2(m+2) \alpha)
\end{aligned}
$$

Where in this equation $\mathrm{m}=1,2,3$. Then:

$$
i_{x 1}=0, i_{y 1}=0
$$

These equations show that $i_{x 1}$ and $i_{y 1}$ are equal to zero. It should be noted that $i_{x 1}$ and $i_{y 1}$ don't contribute in torque production.

By applying the transformation matrix of equation (10) to six-phase currents, the zero sequence currents are as:

$$
\begin{aligned}
& i_{0+}=\frac{1}{\sqrt{2}}\left[i_{1}+i_{2}+i_{3}+\ldots+i_{6}\right] \\
& i_{0-}=\frac{1}{\sqrt{2}}\left[i_{1}-i_{2}+i_{3}+\ldots-i_{6}\right]
\end{aligned}
$$

By substituting the equation (9) in equation (18), the followings are obtained:

$$
\begin{aligned}
& i_{0+}=0 \\
& i_{0-}=\frac{2}{\sqrt{2}}\left[i_{1}-i_{2}+i_{3}\right]
\end{aligned}
$$

Equations (10) to (19) show that x1-yl current components and positive zero sequence current component will be eliminated due to the structure of Figure 2(b).

\section{HYSTSRESIS MODULATION}

The reference currents for hysteresis control are obtained from vector control block diagram of Figure 1. The injected currents from phase 1 to phase 3 are measured and fed back to hysteresis control block. So the switching status of each switch is characterized by the difference between reference current and actual current $(\Delta i)$.

$$
\Delta i_{m}=i_{m}^{*}-i_{m}^{\text {real }} \quad, \quad m \leq 3
$$

The following equation is used for characterizing the status of the switches of each branch:

$$
S_{m}=\left\{\begin{array}{ll}
1 & \Delta i_{m}>b \\
0 & \Delta i_{m}<-b
\end{array} \quad m \leq 3\right.
$$

Where, $S_{m}$ is the status of the switches in $m$ th branch which $\mathrm{m}=1,2$ and 3 , and b is the hysteresis band. Hence, $S_{m}=1$ represent that the upper switch in $m$ th branch is on and the lower switch is off. Similarly, $S_{m}=0$ represent that upper switch is off and lower switch is on.

Determination of the switching status of the switches in the branches with number greater than 3 is derived from the structure of Figure 2(b). As it would be concluded from Figure 2(b), the switching status of the switches in $(m+3)$ th branch is opposite of the switches in $m$ th branch.

So, just the first three phase currents are measured and fed back to the hysteresis block and the switching status of all twelve switches of six-phase inverter would be determined from theses three currents.

$$
S_{m+3}=\left\{\begin{array}{ll}
0 & S_{m}=1 \\
1 & S_{m}=0
\end{array} \quad m \leq 3\right.
$$

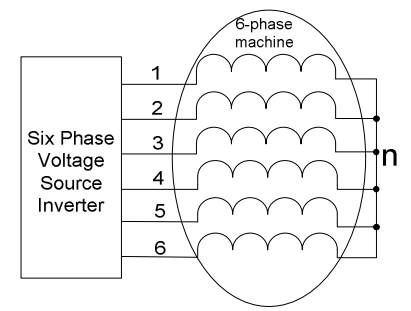

(a)

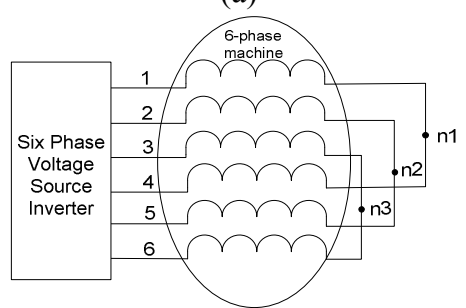

(b)

Fig. 2. Connection diagram of six-phase induction machine: (a) star connected, (b) proposed structure

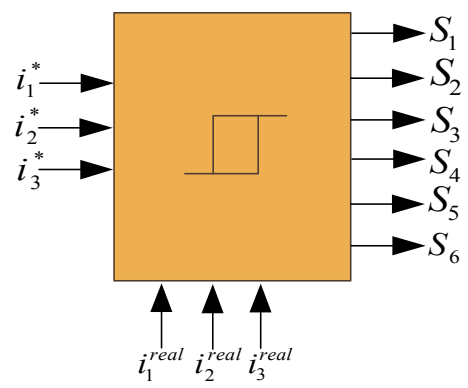

Fig. 3. Hysteresis block diagram ( $S_{m}$ determines the switching status of the $m$ th branch switches) 


\section{SimULATION RESUlTS}

To verify the proposed structure, the vector control of a symmetrical six-phase induction machine is simulated in MATLAB/SIMULINK. The parameters of six-phase machine are represented in appendix I. First in this section, the performance of the vector control of six-phase induction machine with proposed structure is investigated under load variations which the results are shown in Figures 4-6. For this purpose, the six-phase machine connections are similar to Figure 2(b) and just currents of phase 1, phase 2 and phase 3 are fed back to hysteresis block and The switching status of all switches is specified from section V; so the exact control on the current of the other phases is easily achievable. In simulation of this system, the speed command is set to 550rpm; the motor runs under no-load condition and an $11 \mathrm{~N} . \mathrm{m}$ torque is applied to the motor as load at $t=10 \mathrm{~s}$. Figure 4 and Figure 5 show the electromagnetic torque and the speed response of the six-phase induction machine. The current of phase 1, as sample, is illustrated in Figure 6.

As shown in these figures, results verify the performance of vector control with proposed structure under load variation. The simulation results for investigating the performance of vector control under speed command variation are shown in Figures 7-9. In this simulation, the motor works under no-load condition; and the speed command is 550rpm which increases to the $700 \mathrm{rpm}$ at $\mathrm{t}=5.5 \mathrm{~s}$. The electromagnetic torque and speed response are illustrated in Figure 7 and Figure 8. As depicted in Figure 8 , the motor speed follows the speed command. As the vector control is in speed control mode, the motor speed should follow the speed command and should be kept constant under load changes. So, these results verify the vector control of sixphase induction machine using three current sensors with proposed.

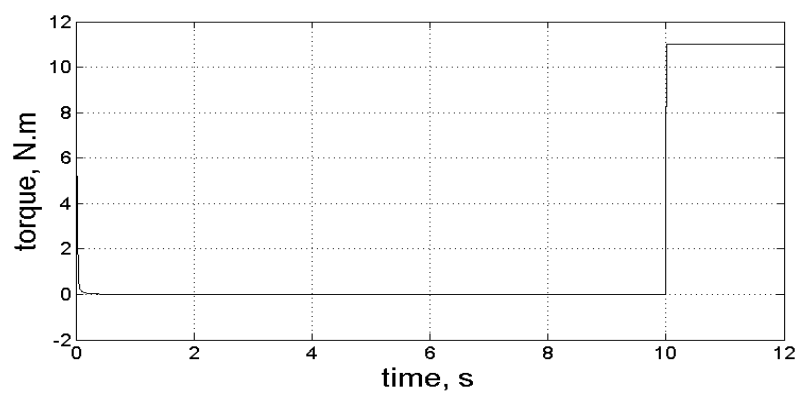

Fig. 4. Electromagnetic torque of symmetrical six-phase induction machine (a load of $11 \mathrm{~N} . \mathrm{m}$ is applied at $\mathrm{t}=10 \mathrm{~s}$ )

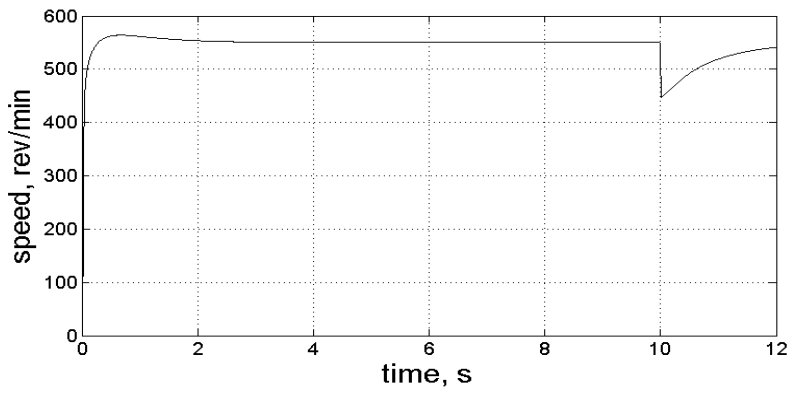

Fig. 5. Speed response of symmetrical six-phase induction machine (the speed command is $550 \mathrm{rpm}$ )

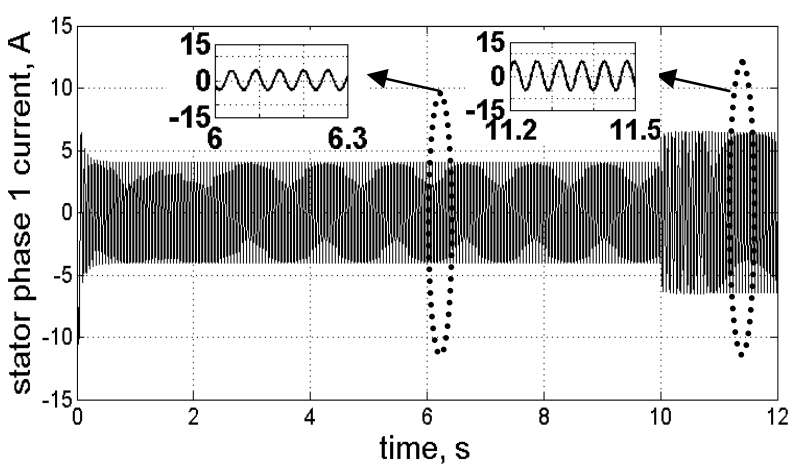

Fig. 6. Phase 1 current (speed command is set to $550 \mathrm{rpm}$ and a $11 \mathrm{~N} . \mathrm{m}$ load is applied at $\mathrm{t}=10 \mathrm{~s}$ )

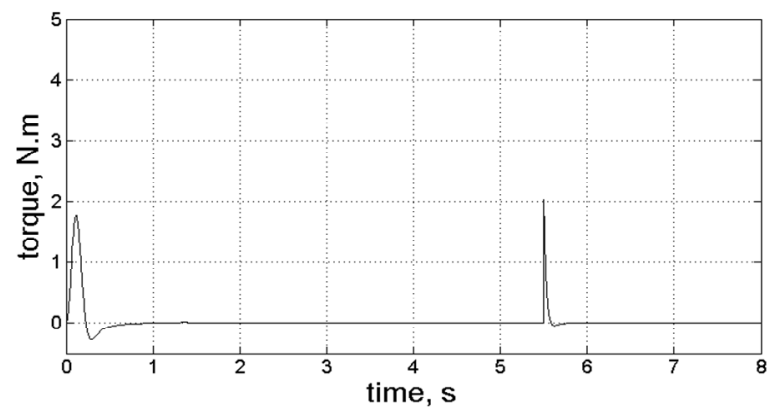

Fig. 7. Electromagnetic torque of symmetrical six-phase induction machine (the motor is working under no-load condition)

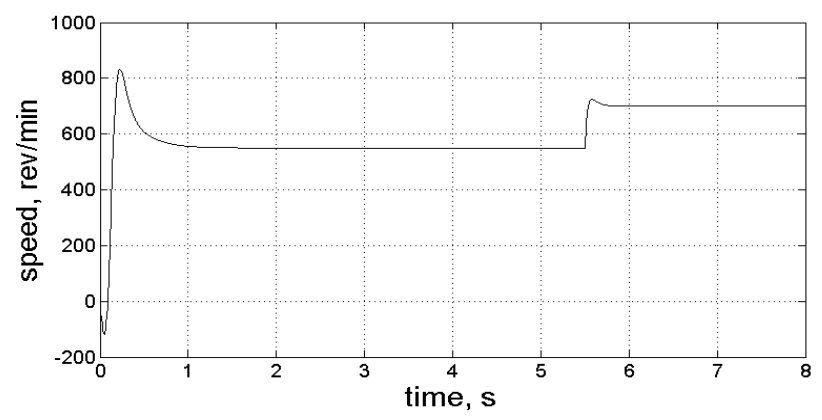

Fig. 8. Speed response of symmetrical six-phase induction machine (the speed command varies from 550rpm to 700rpm at $\mathrm{t}=5.5 \mathrm{~s}$ )

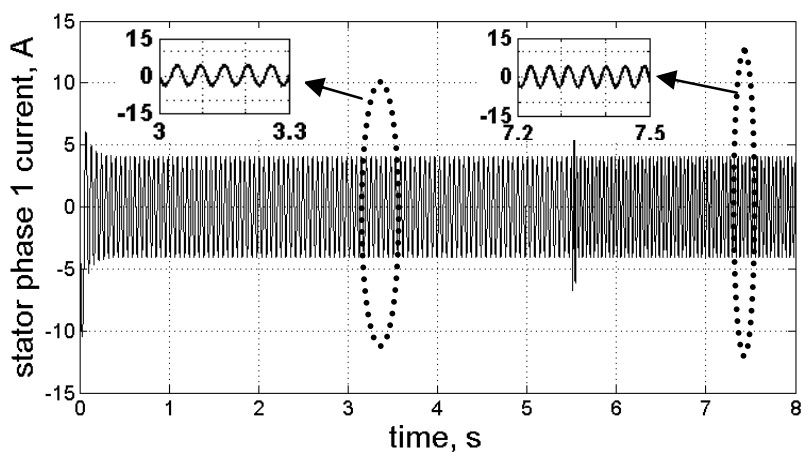

Fig. 9. Phase 1 current (the motor is under no-load condition and the speed command varies from 550rpm to $700 \mathrm{rpm}$ at $\mathrm{t}=5.5 \mathrm{~s}$ ) 


\section{EXPERIMENTAL RESULTS}

An experimental setup is constructed for verifying the application of the proposed structure. In this section, the experimental results of a symmetrical six-phase induction machine are presented. The microcontroller used in controller board is dspic30f4011. Only the first three phase currents, i.e. $\mathrm{i}_{1}, \mathrm{i}_{2}$, and $\mathrm{i}_{3}$, are measured using LEM sensors. The experimental tests have been performed on a six-phase induction machine with 48 slots on stator, 4-pole and $50 \mathrm{~Hz}$. This machine is coupled with a dc generator as load. The perphase parameters of the six-phase induction machine are represented in appendix I. The experimental setup is shown in Figure 10. Motor phase currents are sampled via a data acquisition apparatus (USB-4711A) and the motor speed is measured using digital tachometer RM-1501. Speed and current samples are plotted with MATLAB.

For implementing the proposed structure, the connections of the motor is similar to Figure 2(b) and the current sensors are placed only on the phase 1 , phase 2 and phase 3 . Similar to simulation results, first, the vector control with proposed structure is tested under load variations. For being comparable, the simulation and experimental tests are under same conditions. So, in the first test, the speed command is set to $550 \mathrm{rpm}$ and the load increases from zero to $11 \mathrm{~N} . \mathrm{m}$ at $\mathrm{t}=10 \mathrm{~s}$. The speed is shown in Figure 11. Because of low sampling rate of digital tachometer, the transients in the speed response are not observable. As depicted in Figure 11, the speed is set to 550rpm before and after applying the load. The phase 1 current is illustrated in Figure 12. The test results verify the performance of indirect vector control of symmetrical sixphase induction machine with proposed structure under variations of load and speed command.

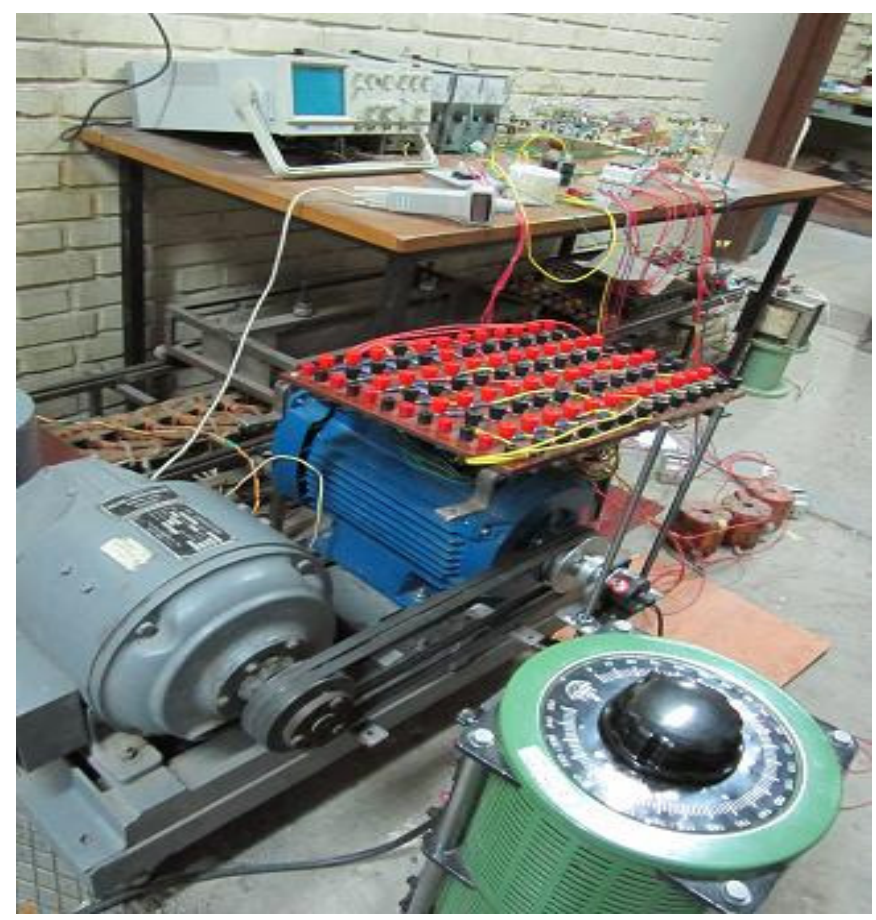

Fig. 10. Experimental setup

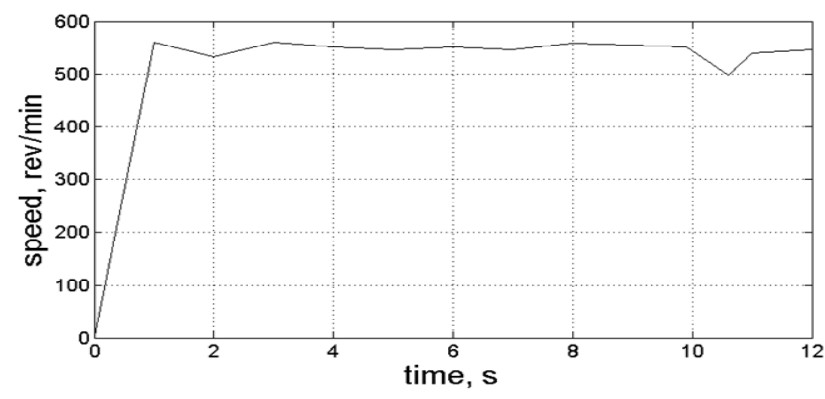

Fig. 11. Speed response of symmetrical six-phase induction machine (the speed command is $550 \mathrm{rpm}$ )

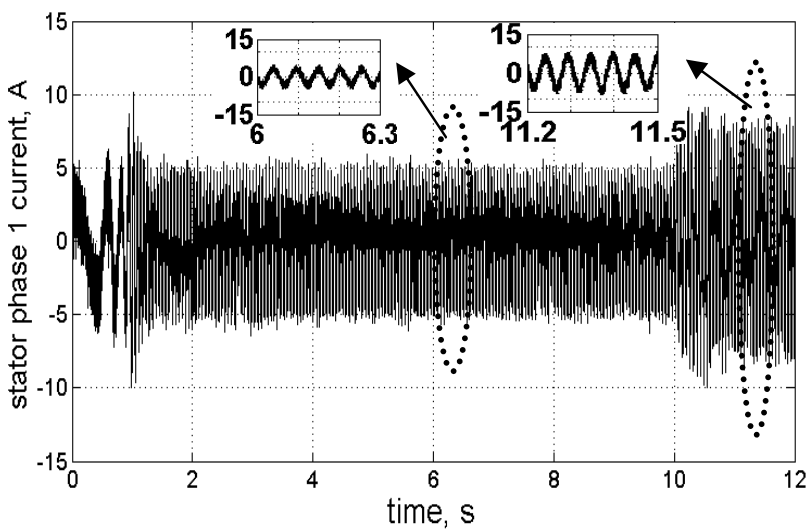

Fig. 12. Measured phase 1 current (speed command is set to 550rpm and a $11 \mathrm{~N} . \mathrm{m}$ load is applied at $\mathrm{t}=10 \mathrm{~s}$ )

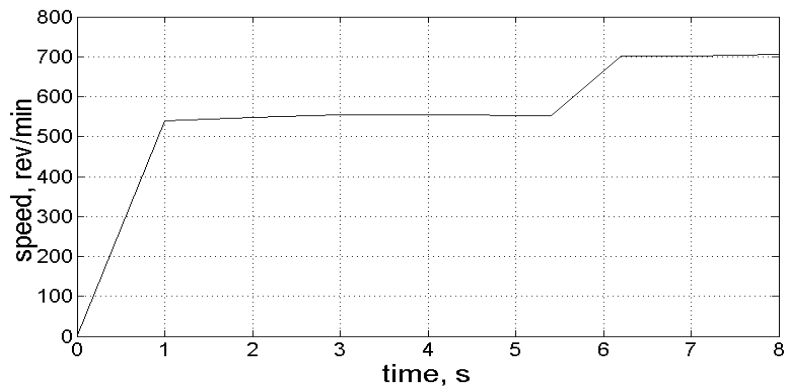

Fig. 13. Speed response of symmetrical six-phase induction machine (the speed command varies from $550 \mathrm{rpm}$ to $700 \mathrm{rpm}$ at $\mathrm{t}=5.5 \mathrm{~s}$ )

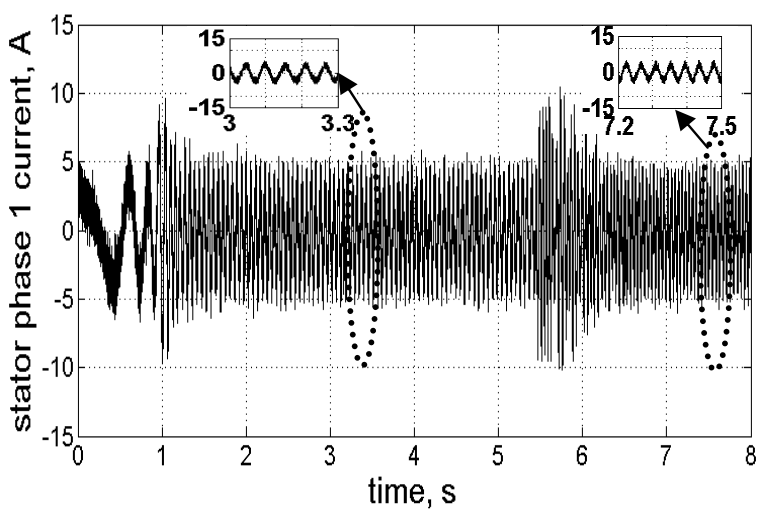

Fig. 14. Measured phase 1 current (the motor is under no-load condition and the speed command varies from 550rpm to $700 \mathrm{rpm}$ at $\mathrm{t}=5.5 \mathrm{~s}$ ) 


\section{CONCLUSION}

This paper presents a new structure for vector control of six-phase induction machines with minimum independent currents. The independent currents are minimized as a result of increasing the neutral points. It should be mentioned that the drawback of this scheme is a little reduction in reliability compared to conventional symmetrical six-phase drive systems while its reliability is still better than three-phase ones. Furthermore, all advantages of six-phase induction machines are retained due to the proposed structure. The analytical equations verify that not only this structure reduces the current sensors, but also yields in eliminating some current components which do not contribute in torque production. With proposed structure, $i_{x 1}, i_{y 1}$ and $i_{0+}$ are equal to zero. Simulation and experimental results verified the performance of vector control of symmetrical six-phase induction machines with proposed structure.

\section{APPENDIX}

The motor parameters are as follows:

$$
\begin{aligned}
& n_{s}=1500 \mathrm{rpm}, p_{n}=3 \mathrm{hp}, r_{r}=0.33 \Omega, r_{s}=0.87 \Omega, \\
& L_{m}=.079 \mathrm{H}, L_{l r}=L_{l s}=2.45 \mathrm{mH}, J=0.028 \mathrm{~kg} . \mathrm{m}^{2} .
\end{aligned}
$$

\section{REFERENCES}

[1] G.K. Singh, "Multi-phase induction machine drive research - a survey", Electric Power Systems Research, Vol. 61, No. 2, pp. 139-147, 2002,

[2] E. Levi, "Multiphase electric machines for variable-speed applications", IEEE Transactions on Industrial Electronics, Vol. 55, No. 5, pp. 1893 1909, 2008.

[3] C. Hodge, S. Williamson, A.C. Smith, "Direct drive marine propulsion motors", ICEM Proc. Int. Conf. on Electrical Machines, Belgium, 2002.

[4] J.M. Apsley, S. Williamson, A.C. Smith, M. Barnes, "Induction motor performance as a function of phase number", IEE Proc.-Electric Power Applications, Vol. 153, No. 6, 2006.

[5] S. Williamson, A.C. Smith, "Pulsating torque and losses in multiphase induction machines", IEEE Transactions on Industry Applications, Vol. 39, No. 4, pp. 986-993, 2003

[6] A.N. Golubev, S.V. Ignatenko, "Influence of number of stator-winding phases on the noise characteristics of an asynchronous motor", Russian Electrical Engineering, Vol. 71, No. 6, pp. 41-46, 2000

[7] H.A. Toliyat, "Analysis and simulation of five-phase variable-speed induction motor drives under asymmetrical connections", IEEE Transactions on On Power Electronics, Vol. 13, No. 4, pp. 748 - 756, 1998.

[8] Jen-Ren Fu, T.A. Lipo, "Disturbance-free operation of a multiphase current-regulated motor drive with an opened phase", IEEE Transactions on Industry Applications, Vol. 30, No. 5, pp. 1267 - 1274, 1994.

[9] A.C. Smith, S. Williamson, C.G. Hodge, "High torque dense naval propulsion motors", IEMDC Proc. IEEE International Electric Machines and Drives Conf., Vol. 3, pp. 1421-1427, 2003
[10] R.O.C. Lyra, T.A. Lipo, "Torque density improvement in a six-phase induction motor with third harmonic current injection", IEEE Transactions on Industry Applications, Vol. 38, No. 5, pp. 1351-1360, 2002

[11] E. Levi, M. Jones, S.N. Vukosavic, H.A. Toliyat, "A novel concept of a multiphase, multimotor vector controlled drive system supplied from a single voltage source inverter", IEEE Transactions on Power Electronics, Vol. 19, No. 2, pp. 320-335, 2004.

[12] E. Levi, M. Jones, S.N. Vukosavic, "Even-phase multi-motor vector controlled drive with single inverter supply and series connection of stator windings", Proc. IEE-Electric Power Applications, Vol. 150, No. 5, pp. 580-590, 2003.

[13] M.B. de Rossiter Correa, C.R. da Silva, H. Razik, C.B. Jacobina, E.R.C. da Silva, "Independent voltage control for series-connected six- and three-phase induction machines", IEEE Transactions on Industry Applications, Vol. 45, No. 4, pp. 1286-1293, 2009.

[14] W. Leonhard, Control of electrical drives, Berlin, Germany: SpringerVerlag, 1985.

[15] M.E.H. Benbouzid, D. Diallo, M. Zeraoulia, "Advanced fault-tolerant control of induction-motor drives for ev/hev traction applications: from conventional to modern and intelligent control techniques", IEEE Transactions on Vehicular Technology, Vol. 56, No. 2, pp. $519-528$, 2007.

[16] I. Kioskeridis, N. Margaris, "Loss minimization in scalar-controlled induction motor drives with search controllers", IEEE Transactions on Power Electronics, Vol. 11, No. 2, pp. 213 - 220, 1996.

[17] F. Blaschke, "The Principle of field-orientation as applied to the new 'transvector' closed loop control system for rotating-field machines", Siemens Review, Vol. 34, No.. 5, pp. 217-220, 1972.

[18] K. Hasse, About the dynamics of adjustable-speed drives with converterfed squirrel-cage induction motors, (in German), Ph.D. Dissertation, Darmstadt Technische Hochschule, 1969.

[19] E. Levi, R. Bojoi, F. Profumo, H.A. Toliyat, S. Williamson, "Multiphase induction motor drives-a technology status review", IET Electric Power Applications, Vol. 1, No. 4, pp.489-516, 2007.

[20] A. Iqbal, E. Levi, "Space vector PWM Techniques for Sinusoidal Output Voltage Generation with a Fve-Phase Voltage Source Inverter", Electric Power Components \& Systems, Vol. 34, No. 2, pp. 119-140, 2006

[21] E.A. Klingshirn, "High phase order induction motors - part I- description and theoretical considerations", IEEE Transactions on Power Apparatus and Systems, Vol. PAS-102, No. 1, pp. $47-53,1983$.

[22] S.N. Vukosavic, M. Jones, E. Levi, J. Varga, "Rotor fux oriented control of a symmetrical six-phase induction machine", Electric Power Systems Research, Vol. 75, No. 2-3, pp. 142-152, 2005.

[23] R. Bojoi, A. Tenconi, G. Griva, F. Profumo, "Vector control of dual three-phase induction motor drives using two current sensors", IEEE Transactions on Industry Applications, Vol. 42, No. 5, pp. 1284 - 1292, 2006.

[24] S. N. Vukosavic, A. M. Stankovic, "Sensorless induction motor drive with a single dc-link current sensor and instantaneous active and reactive power feedback", IEEE Transactions on Industry Applications, Vol. 48, No. 1, pp. $195-204,2001$.

[25] A. M. Trzynadlowski, Control of induction motor, San Diego, USA: Academic Press, 2001.

[26] M. Jones, S. N. Vukosavic, E. Levi, A. Iqbal, "A six-phase seriesconnected two-motor drive with decoupled dynamic control", IEEE Transactions on Industry Applications, Vol. 41, No. 4, pp. 1056-1066, 2005 . 